\title{
Einstein's Theories.
}

\begin{abstract}
THE Revue Philosophique (Alcan, Paris), edited by Prof. Lévy-Bruhl, has just issued (JulyAugust) a special number devoted to the consideration of Einstein's theories of relativity. It consists of four articles of exceptional ability and importance, all directed to the philosophical aspects of the problem. That Einstein's theory is established, in the meaning that it is applicable in physical science, is accepted by each of the writers, and their aim is to decide how far it forces upon us a new way of thinking about physical reality.
\end{abstract}

The first article is a translation by M. Léon Bloch from the German of Hans Reichenbach, " La signification philosophique de la théorie de la relativité." The philosophical interest centres on the concept of time. Must we give up the absolute meaning of simultaneity? If we do, the Michelson-Morley experiment at once ceases to be incomprehensible, light can have the same velocity in the moving system which it has in the system at rest. But can we give up absolute simultaneity without being involved in logical difficulties and finding ourselves confronted with a pure paradox? In a very skilful argument the writer concludes that we can and that we must. Relativity is both a logical necessity and an experimental fact. This leads to the consideration of the part played by the velocity of light in Einstein's theory.

In Nature the electromagnetic waves play a unique part and are of greater importance than any other phenomenon which serves us as a signal. They alone (if we set aside gravitation) transmit an action across empty space. Now as the forces which the individual particles of matter exercise on one another are of the same nature as electromagnetic forces, it follows that all propagation of material action resolves itself ultimately into an electrical transmission.

The essential ideas of the theory of relativity were forestalled by Ernst Mach forty years ago, and Einstein is continually reminding us of our indebtedness to him. The idea that movement as a spatial phenomenon can be recognised only in relation to other bodies was much older-we have it, for example, in Descartes and in Leibniz-but what distinguishes Mach's point of view is the idea that movement must have not only kinematic but also dynamic relativity, that what we call the forces of inertia must be bound up with the presence of other bodies. In Mach, however, the relativity of theory of knowledge is not distinguished from physical relativity; it remained for Einstein to show that the actions of movements, or what we name forces, can be reduced to a difference between the distributions of masses.

The second article, by M. G. Cerf, "Pour l'intelligence de la relativité," deals particularly with the exact meaning we are to give to the terms employed in the theory, and the writer draws largely on the works of Henri Poincaré.

The third article, "Einstein et la métaphysique," is by M. Edmond Goblot, the distinguished logician and philologist. He finds considerable amusement and no little instruction in the popularisers of Einstein, more especially those who competed for the Higgins prize of the Scientific American Publishing Co. In his conclusion he says: "Je résume et précise ma question: Einstein est-il mathématicien, physicien ou métaphysicien? Mathématicien il l'est. Physicien il l'est aussi. S'est-il borné à cela, ou s'est-il abandonné aux débauches de métaphysique inconscient qu'on nous fait lire en son nom? Dans les deux cas, il est grand temps d'exorciser tous ces fantômes."

The fourth and concluding article, by M. RichardFoy, "Le temps et l'espace du commun sens," is a very clear statement of the whole problem to meet which the new principle is required. It deals mainly and sympathetically with M. Painlevé's protest against the refusal to allow any place for the concept of an absolute in physics. The rejection of time and space as absolutes is not irreconcilable, he argues, with such a position. To say that time, space, and movement are not absolutes means that, instead of being realities which impose their laws on phenomena, they are only abstractions, necessary to express those laws, but capable of assuming the most diverse forms. We choose among these forms with the simple aim of discovering the most convenient, but our choice has limits. For example, we cannot define simultaneity in any two points absolutely, yet we must define it so that it is not possible that my friend has read my letter to him before $I$ have written it.

\section{Educational Work of the Ministry of Agriculture.}

THE Intelligence Department of the Ministry of Agriculture and Fisheries has issued a Report on the work of the department for the years I919I92I, which is published at the price of $5 \mathrm{~s}$. by H.M. Stationery Office. The duties of this department are concerned with agricultural education, agricultural research, the agricultural training of ex-officers and men, horticulture, the improvement of live-stock, the destruction of rats, and the diseases of animals.

Agricultural education is provided through the agency of colleges, including agricultural departments of universities, and by farm institutes, local classes, and lectures. The first group comprises eleven institutions, of which all, except the Harper Adams, the Midland Agricultural College, the University College, Reading, and the Seale Hayne College, are connected with universities in which students may obtain a degree with agricultural science as their chief subject. In most cases the agricultural department is actually part of the university organisation, and it is recognised that in many respects this is an ideal arrangement. Agricultural students thereby obtain the intellectual stimulus that is associated with intercourse with students in other faculties. Future teachers, scientific workers, and agricultural experts all gain by the indefinable atmosphere which pervades a university course. On the other hand, it has been found that although, theoretically, expenditure should be saved by taking advantage of the courses in general science which a university provides, in actual practice it has proved necessary to provide special teaching even in preliminary scientific subjects designed for agricultural students.

By means of this special teaching an agricultural flavour is imparted to chemistry, botany, zoology, or whatever the fundamental science may be, and thus from the very beginning the student's interests are awakened and stimulated. Against such an arrange- 
ment it has been urged that association with other students tends to divert a certain number of agricultural men to other subjects. But it is probable that an agricultural department of a university tends to attract more men than it loses. The courses provided in university departments of agriculture are intended for the education of future landowners, land agents, and large farmers, but for investigators it is found best that they should pass through an honours school in pure science before taking up the study of the application of science to agriculture. The report lays special emphasis on the need for the study of accountancy, which in its application to costs of production may be a powerful instrument in determining the economic success of a farm.

It is pointed out that the cost of providing the necessary staffs in a university or college is now so great that it is impossible for each college to provide highly specialised instruction in every branch of agricultural education, but that extreme specialisation must be left to individual colleges. Again, tutorial instruction and encouragement of private reading are urged as a means of relieving pressure on formal lectures, and so of keeping down expenses.

While agricultural departments in universities and agricultural colleges are the agency of providing instruction to prospective landowners, large farmers, and public servants, the needs of the ordinary farmer's son are best supplied through farm institutes. The latter have been developed in recent years as the result of the recommendations of Lord Reay's Committee which in I905 strongly urged their creation. These farm institutes are under the authority of County Councils, directed by the Ministry of Agriculture. An agricultural education committee having been set up, it submits its scheme to the ministry, and this, if approved, is supported by grants. The staff of an institute consists in most cases of an organiser, a director of agriculture, and certain teachers. The county organiser is usually the head of the farm institute, and towards his salary the ministry may contribute as much as four-fifths. It also pays annual grants up to two-thirds of the total general expenditure. Classes are provided as a rule for twenty-four weeks during winter, at a time, namely, when young farmers can leave their farms and devote their time to study. While a certain amount of manual training is possible at farm institutes, it is recognised that the best place for getting such instruction is on the farm of the student's father. The teaching of science is in close contact with practice, and is concerned principally with such subjects as varieties of crops, methods of cultivation, rotations, manures and feeding stuffs, principles of feeding and breeding, dairying, poultry, and farm book-keeping. Such farm institutes have been established in Cumberland, Essex, Hampshire, Carnarvonshire, Monmouthshire, Cheshire, Hertfordshire, Northamptonshire, Somerset, Staffordshire, Suffolk, and Denbigh, while others are contemplated in Durham, Kent, Carmarthen, West Sussex, and the Holland Division of Lincolnshire.

Besides providing instruction for students, the colleges and institutes are intended to serve as advisory centres for farmers generally. Such advisory officers are usually specialists in plant pathology, botany, chemistry, and general agriculture, and to these farmers are encouraged to turn in case of difficulty. This they are doing in increasing numbers every year, and one of the most gratifying features of the present position is the disappearance of prejudice on the part of cultivators to education and science.

$$
\text { NO. } 2759 \text {, VOL. [IO] }
$$

\section{University and Educational Intelligence.}

ABERDEen.-Mr. G. P. Thomson, lecturer in mathematics at Corpus Christi College, Cambridge, has been appointed professor of natural philosophy in succession to Prof. C. Niven, who has retired.

LEEDS.- The honorary degree of Doctor of Science has been awarded to Prof. A. F. Holleman, of the University of Amsterdam.

Prof. Charles Crowther has been appointed Principal of the Harper-Adams Agricultural College, Newport, Salop, in succession to Mr. P. Hedworth Foulkes, who has been Principal since the College opened in I90o.

AN important conference of representatives of British and Swiss universities took place at Basle last month. There were present fifteen delegates from Great Britain and Ireland, Oxford being represented by the Vice-Chancellor and the Warden of All Souls, Manchester by the Vice-Chancellor and Prof. T. F. Tout, Edinburgh by Sir Richard Lodge and Prof. J. Mackinnon, and Birmingham, Bristol, Cambridge, Leeds, London, Wales, St. Andrews, Dublin, and the National University of Ireland each by one delegate. Each of the seven Swiss cantonal universities was represented. At the three formal sessions of the conference, held on August 22 and 23 in the great hall of the University, the topics of discussion were the recognition by the British universities of university entrance examinations passed, university studies pursued, and degrees conferred in Switzerland, and vice versa, and interchange of university teachers. Of perhaps even greater importance than the formal discussions were the conversations for which ample opportunities were provided in the course of the numerous social functions at which the visitors were entertained. The Federal Ecole Polytechnique of Zürich was unfortunately not represented at the conference. Before the war this institution, like the cantonal universities, drew a large proportion of its students from other countries where economic conditions are at present unfavourable to the migration of students to Switzerland. Consequently there are plenty of vacant places in its laboratories, which are well equipped for advanced work in, for example, industrial chemistry and electrical engineering.

A PROVISIONAL programme has been issued by the Sociological Society, Leplay House, 65 Belgrave Road, Westminster, S.W.I, of a conference on the correlation of the social sciences, which it is proposed to hold at Oxford on October 7-9. The conference will not be open to the public, but invitations are being issued to members of the Sociological Society and to representatives of the social sciences from the universities of Great Britain. The object of the conference is to provide an opportunity for the discussion by specialists of various branches of social science with the view of co-ordination. Mr. F. S. Marvin (history), Sir Halford Mackinder (geography), Mr. Julian Huxley (biology), Prof. C. E. Spearman (psychology), Prof. L. T. Hobhouse (philosophy), Dr. R. R. Marett (anthropology), Prof. J. E. G. de Montmorency (law), and the Rev. A. J. Carlyle (political science), will probably address the conference, dealing with the various aspects of sociology named. 